\title{
Hydrogen Embrittlement in Bearing Steels
}

\author{
Miles Alexander Stopher ${ }^{\mathrm{a}}$, Pedro E. J. Rivera-Diaz-del-Castillo ${ }^{\mathrm{a}}$ \\ ${ }^{a}$ SKF University Technology Centre, Department of Materials Science and Metallurgy, \\ University of Cambridge, 27 Charles Babbage Road, Cambridge, CB3 OFS
}

\begin{abstract}
Hydrogen embrittlement is, and has been for over a century, a prominent issue within many sectors of industry. Despite this, the mechanisms by which hydrogen embrittlement occurs and the suitable means for its prevention are yet to be fully established. Hydrogen embrittlement is becoming an ever more pertinent issue. This has led to a considerable demand for novel hydrogen embrittlement resistant alloys, notably within the bearings industry.

This paper provides an overview of the literature surrounding hydrogen embrittlement in bearing steels, and the means by which manufacturers may optimise alloys and accompanying processes to prevent embrittlement. Notably, novel steels combining both high strength and hydrogen embrittlement resistance are reviewed with respect to their design, evaluation methods, and required future work.
\end{abstract}

Keywords: Hydrogen Embrittlement, Bearing Steel, Microstructure, Rolling Contact Fatigue, Damage, Alloy Design

\section{Introduction}

Hydrogen-induced degradation manifests itself in numerous ways, such as the catastrophic failure of high-strength steels [1], the contribution to stress corrosion cracking of various materials [2], and the failure of zircalloy fuel cladding in nuclear reactors by hydride formation [3] among others. Despite significant research in recent decades, hydrogen-induced degradation is still not fully understood. Although a number of mechanisms have been postulated and consequently extensively investigated in the literature, the evidence on the fundamental mechanisms and the true causes of hydrogen-induced degradation remain inconclusive. The most supported and consequently heavily investigated are those of hydrogen enhanced decohesion (HED) [4] 
and hydrogen enhanced localised plasticity (HELP) theory [5]. Despite the lack of a conclusive theory, it is established that hydrogen enhances plasticity local to crack tips, increases slip deformation and reduces the critical stress required to propagate cracks [6].

Hydrogen-enhanced fracture is a considerably complex problem, with the contradictory behaviour of microscale ductility leading to brittle fracture [7]. This complexity is further extended by the ingress-dependence and microstructural-dependence of the resultant mechanisms [8]. For example, the hydrogen diffusivity, dependent upon the trapping characteristics of features such as grain boundaries and precipitate interfaces, will depend upon the coherency of the respective boundaries [9] [10]. Coupling these structural features' trapping behaviour with the effects hydrogen has on said features' strength [11], predicting hydrogen-enhanced crack initiation and propagation becomes complex. In addition to these microstructural dependencies, the nature of crack initiation and subsequent growth is governed by the external stresses applied, the temperature and the alloy strength, resulting in a range of possible mechanical reactions from grain boundary decohesion [12] to precipitate shear [13]. This results in a challenging division for stress to strain criteria in hydrogen-induced failures, and indicates that various phenomena could be postulated for the same failure. It is this complexity, and the lack of conclusive hydrogen-induced failure mechanisms, which has resulted in hydrogen embrittlement remaining a largely misunderstood phenomenon.

This paper provides a review of the current literature regarding hydrogen embrittlement of relevance to designing hydrogen embrittlement resistant bearing steels, including the fundamentals of rolling contact fatigue (RCF) [14], microstructural design [15] and the experimental techniques available for the assessment of hydrogen embrittlement [16]. Included, is a description of the primary mechanisms of hydrogen ingress and proceeding embrittlement as postulated in the literature, identifying corresponding experimental evidence, discrepancies and relevant knowledge gaps.

\section{Mechanisms of Hydrogen Ingress}

The ingress of hydrogen into steels can occur in a number of ways, varying with the respective environment [17]. To better develop hydrogen resistant bearing steels, it is first necessary to establish the mechanisms by which hydrogen forms, enters and diffuses through the material. As it will be shown, almost all instances of hydrogen embrittlement begin with the decomposition 
of molecules into hydrogen at the material surface, the exception being those already in a hydrogen-rich environment where diffusion of atomic hydrogen directly into the bulk dominates [17]. The following subsections, based upon open literature, present the most common mechanisms of hydrogen ingress, their current means of prevention and any source-specific effects.

\subsection{Ingress From Lubricant Decomposition}

The mechanism of hydrogen ingress thought to be most prevalent to bearings, the decomposition of lubricant oil, occurs under the repeated stresses and resulting heat of bearing operation [18]. As will be discussed later, it is well known that white etching structures, often termed white etching areas (WEA), form directly underneath the rolling contact surface, becoming initiation sites for subsurface cracks often leading to bearing failure [19]. A study conducted by Kino and Otani [20] investigated the cause of such regions with respect to bearing failure due to flaking, focusing primarily on the effects of hydrogen content. Thrust ball bearings having raceways of SCM420H steel (Table 1), a surface carburisation hardened mild carbon steel, and balls of SUJ2 steel, a high-carbon chromium alloy steel, with surface hardnesses of 720 and $770 \mathrm{HV}$ respectively, were tested in two different traction fluid oils, both containing different additives. The composition of said oils was not disclosed, neither were the compositions of the steels, though said steel grades' typical compositions are shown in table 1. It was found that the decomposition of both oils resulted in hydrogen ingress into the steels causing hydrogen-enhanced failure. However, oil no.1 produced greater amounts of hydrogen upon decomposition in an identical testing environment to that of

oil no.2; this highlights the importance of oil composition on the resulting hydrogen ingress. The results are shown in Figure 1, indicating the hydrogen content of the steels before and after testing in both oils.

A more detailed example of oil decomposition, that of synthetic hydrocarbon oil (1, 2, 4-Tris (2-Octyl-1-Dodecyl) Cyclopentane), was presented with respect to 100Cr6 bearing steel, a typical composition of which is shown in Table 1, demonstrating the process by which hydrogen ingress occurs [22]. Under feasible rolling conditions, decomposition was shown to result in the formation of hydrogen and hydrogenous products: $\mathrm{CH}_{3}{ }^{+}, \mathrm{C}_{2} \mathrm{H}_{3}{ }^{+}, \mathrm{C}_{2} \mathrm{H}_{4}{ }^{+}$ and $\mathrm{C}_{3} \mathrm{H}_{7}{ }^{+}$, promoting hydrogen diffusioninto the bulk of steel [23]. Diffusion into the bulk is permissible due to the electropotential with respect to the nascent surface caused by the breakdown of oxides, a result of friction, vibration and/or electrolysis. Evidently, there are multiple competing species 
Table 1 Common commercial bearing steels [21].

\begin{tabular}{llllllllll}
\hline Grade & $\mathrm{C}$ & $\mathrm{Mn}$ & $\mathrm{Si}$ & $\mathrm{Cr}$ & $\mathrm{Ni}$ & $\mathrm{Mo}$ & $\mathrm{Cu}$ & $\mathrm{S}$ & $\mathrm{P}$ \\
\hline 100Cr6 & 0.98 & 0.38 & 0.16 & 1.39 & 0.07 & 0.02 & 0.12 & 0.06 & 0.12 \\
AISI 1070 & 0.71 & 0.76 & 0.20 & 0.09 & 0.08 & 0.02 & 0.07 & 0.012 & 0.006 \\
ShKh4 & 0.98 & 0.18 & 0.17 & 0.38 & $\ldots$ & $\ldots$ & $\ldots$ & $\ldots$ & $\ldots$ \\
ShKh15 & 1.05 & 0.28 & 0.28 & 1.5 & 0.11 & & 0.06 & 0.015 & 0.013 \\
SUJ2 & 1.03 & 0.37 & 0.23 & 1.35 & 0.51 & $\ldots$ & 0.15 & 0.023 & 0.018 \\
100CrMo7-3 & 0.97 & 0.66 & 0.27 & 1.79 & 0.11 & 0.26 & 0.15 & 0.007 & 0.009 \\
52CB & 0.85 & 0.35 & 0.85 & 0.90 & $\ldots$ & 0.60 & $\ldots$ & $\ldots$ & $\ldots$ \\
SCM420H & 0.20 & 0.75 & 0.25 & 1.05 & 0.25 & 0.23 & 0.30 & $<0.03$ & $<0.03$ \\
\hline
\end{tabular}
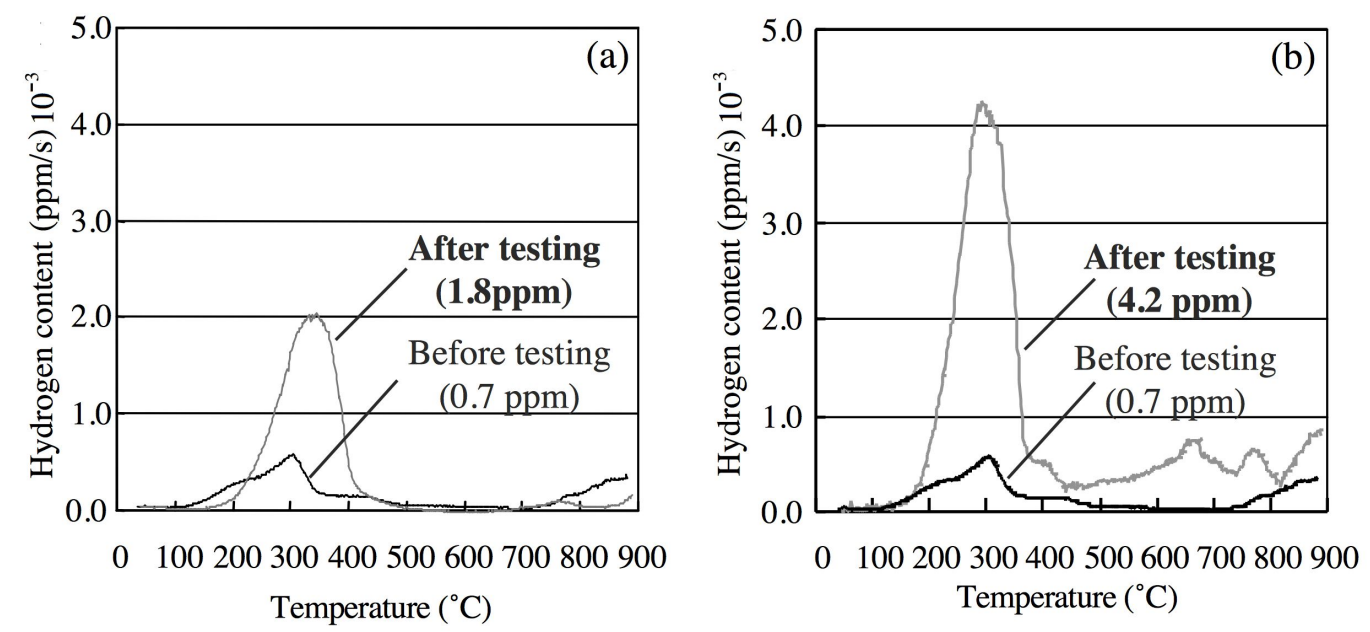

Figure 1: Thermal desorption analysis data of SCM420H steel subjected to hydrogen ingress from the decomposition of two different oil compositions (a) oil no.1 and (b) oil no.2, which remain undisclosed [20].

for adsorption onto the steel surface, and as such hydrogen absorption is retarded, as evidenced in the Iyer-Pickering-Zamanzadeh-Al-Faqeer (IPZA) model [24].

As shown in Figure 2, active sites are generated upon the nascent surface of the bearing steel after the removal of the oxide layer due to rubbing [23]. Tribochemical decomposition of the oil then occurs upon these active sites with hydrogen and gaseous hydrocarbons desorbed as reaction products. The desorbed amount of hydrogen and hydrocarbons increases linearly with rolling velocity and parabolically with load [23]. In addition, there ap- 
pears a critical load beyond which decomposition occurs [23]. The ratio of desorbed gaseous hydrogen to hydrogen remains unaffected by the variations in rolling conditions tested. It should be noted that lubricants containing water are also liable to induce hydrogen embrittlement due to water splitting by electrolysis [25].
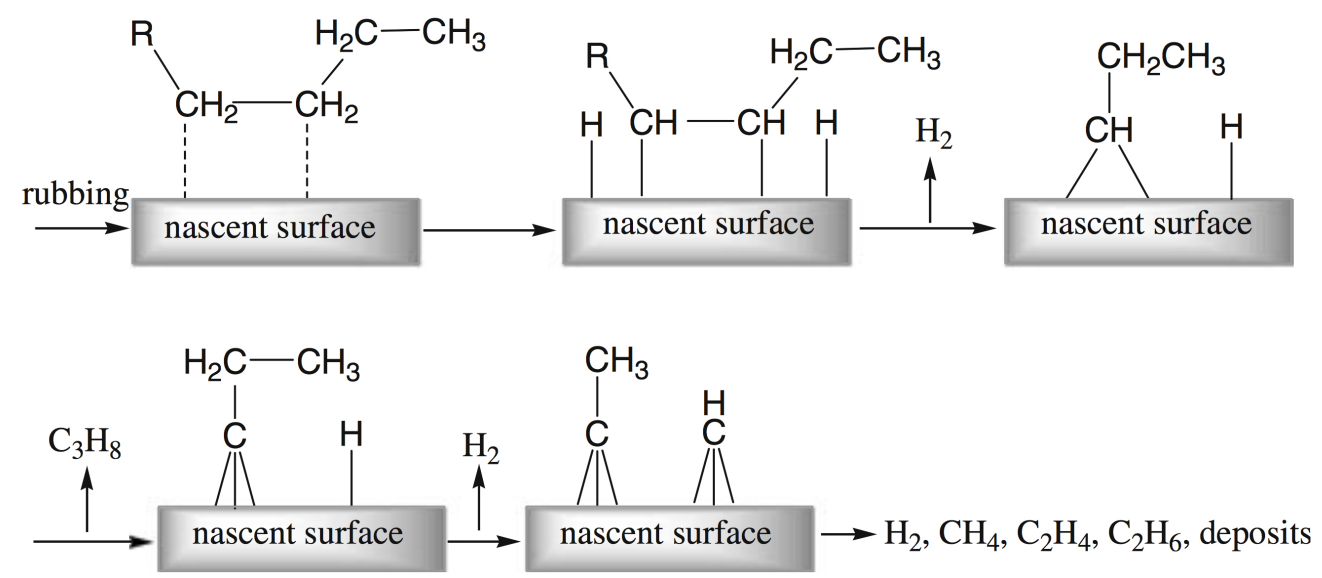

Figure 2: Chemical reactions on a 100Cr6 bearing steel's nascent surface due to oil decomposition [23].

In summary, it is evident that both oil composition and rolling conditions affect the decomposition of oil and the resulting hydrogen absorption. Limited data are available on the decomposition of oil with respect to hydrogen production and absorption. As such, it is difficult to simulate the respective reactions of hydrogen in relevant operating environments for use in hydrogencharging experiments and as shown, given the numerous variables, it is likely that this should be done on a case-by-case basis. Thus, the development of hydrogen-resistant lubricants can be of as much importance as the development of hydrogen embrittlement resistant bearing steels in improving rolling contact fatigue life.

\subsection{Ingress During Processing}

The ingress of hydrogen into molten steel can occur through reactions with water and hydrogen bearing compounds, often included in the feedstock [26]. The control of hydrogen content in steels is an important task for steelmakers, just a few parts per million of dissolved hydrogen can induce 
hydrogen flakes (hairline cracks), blistering, loss of ductility and increased porosity [27], especially in larger castings [28].

Steelmakers pay significant attention to the elimination of hydrogen by degassing treatments, both within the steel bath and post casting [28]. For molten steel, a vacuum treatment encourages the formation of gas bubbles containing hydrogen, nitrogen and gaseous oxides. These bubbles rise to the top of the molten steel and are separated from the steel bath. In addition, argon bubbling will also enhance hydrogen egress by reducing the hydrogen partial pressure in the melt [29]. For cast steel, a simple hydrogen bake-out treatment is often carried out by heating the steel, typically at low temperatures $\left(150\right.$ to $230^{\circ} \mathrm{C}$ ) for a long period of time (typically 12 to 48 hours) [30] so as to prevent detrimental microstructural changes, for a period of time dependent upon the cleanliness of the melt [28]. However, degassing at a low temperature $\left(<200^{\circ} \mathrm{C}\right)$ can liberate weakly trapped hydrogen and concentrate it in deeply trapping microstructural features, which can, in some cases, increase the embrittlement susceptibility due to higher stress concentrations [31].

In addition to degassing treatments, steelmakers will also take into account the following influences on hydrogen egress:

- Melt method (a steel's hydrogen concentration at the end of an electric arc furnace melt will on average be up to 4 ppm greater in comparison to that of top blowing converters [26]).

- The use of lime or aluminium-lime (scavenging moisture from the environment and into the slag[29]).

- The use of oxygen blowing (reducing hydrogen content via the combustion of carbon [32]).

- The quality of scrap used (rusted material will increase hydrogen content $[14])$.

- The use of un-preheated ladles, new linings and lime during tapping (all of which increase hydrogen content[29]).

The detrimental effects of hydrogen can begin to be observed even upon solidification, commonly through hydrogen flake formation [27]. Due to the higher solubility of hydrogen in steel at higher temperature, molecular hydrogen will form upon solidification and cooling [29]. This gas forms pressure 
raisers within the matrix, inducing defects that in turn can cause failure [28]. Hydrogen flakes begin to appear once the steel reaches $200^{\circ} \mathrm{C}$, forming upon defects such as inclusions and areas of martensite and segregation, with manganese additions significantly increasing the steel's susceptibility. Sulphur also affects the steel's susceptibility to hydrogen cracking. Reductions in sulphur amounts can increase hydrogen content on the now limited number of inclusions, often reaching a critical limit beyond which cracking occurs [33][29].

The casting process is not the only source of hydrogen ingress during processing; hydrogen absorption is observed after surface treatments like pickling and electroplating [34]. Of course, hydrogen ingress during steel processing is a far broader subject than is appropriate to cover in this paper [28][27][29][35]. However, by identifying the contributing factors to hydrogen ingress, steels can be developed alongside their respective processes, and optimised accordingly to prevent hydrogen embrittlement.

\subsection{Ingress due to General Corrosion and Internal Decarburisation Effects}

The formation of rust is known to induce hydrogen ingress into steels, the reaction for which is shown below [36].

$4 \mathrm{Fe}^{2+}+\mathrm{O}_{2}+6 \mathrm{H}_{2} \mathrm{O} \rightarrow 4 \mathrm{FeOOH}+8 \mathrm{H}^{+}$

$\mathrm{Fe}^{3+}+3 \mathrm{H}_{2} \mathrm{O} \rightarrow \mathrm{Fe}(\mathrm{OH})_{3}+3 \mathrm{H}^{+}$

The formation of rust is of course temperature and environment dependent [37]. However, as the operating temperatures increases, the formation of rust is not the only chemical reaction that needs to be considered. At high temperature, due to high hydrogen mobility through interstitial sites, hydrogen atoms may begin to form molecular hydrogen, depending on the reaction site, causing blistering [26]. More specifically, when at temperatures above $200^{\circ} \mathrm{C}$, internal decarburisation, stated as "internal" to differentiate it from surface decarburisation during heat treatment, can occur from the reaction of molecular hydrogen with carbon atoms [38] or carbides such as cementite, forming methane, as shown [36]:

$\mathrm{C}+2 \mathrm{H}_{2} \rightarrow \mathrm{CH}_{4}$

$\mathrm{Fe}_{3} \mathrm{C}+2 \mathrm{H}_{2} \rightarrow 3 \mathrm{Fe}+\mathrm{CH}_{4}$

This methane, in a similar way to molecular hydrogen, forms gas voids within the matrix and promotes the formation of cavities, blisters and cracks due to the resulting internal stress [39]. Given the larger molecular size of methane, these effects are more severe than that of molecular hydrogen. 
However, molecular hydrogen may also react with free oxygen and oxides to form water, resulting in further increases in internal stress [40].

In all cases, once hydrogen has entered the material, it diffuses through a combination of both self-diffusion, driven by concentration gradients and described by Fick's laws of diffusion, and physiochemical interactions with microstructural features such as hydrogen traps [41]. Such traps have higher binding energies to hydrogen than those of regular interstitial sites within the matrix and can trap hydrogen either reversibly or irreversibly, depending on the magnitude of the binding energy [42]. It is these hydrogen traps, and their ability to prevent further hydrogen migration, leading to potentially detrimental interactions, which show most promise in the search for hydrogen-resistant steels [42] [15]. The following two sections outline these trapping mechanisms, as presented within the literature, identifying suitable traps for future investigation along with the modelling techniques available to evaluate said suitability.

\section{Designing Hydrogen Embrittlement Resistant Microstructures}

It is well established that immobilised hydrogen does not contribute to hydrogen embrittlement in its general case [43]. Thus, the state of the respective hydrogen within the steel is critical with regards to its contribution to hydrogen embrittlement. The proportions of hydrogen in the mobile and immobile states depend on the microstructure of the respective steel, defining the solubility, transport and trapping of hydrogen within said steel. The following section explains these terms both qualitatively and quantitively with respect to hydrogen embrittlement susceptibility and proposes a primary route through which such susceptibility can be reduced.

Bearing steels contain complex microstructures, the modelling of which has improved significantly in recent years with advances in thermodynamic and kinetic modelling [44] [45]. As such, these microstructures contain defects and features such as grains and numerous phases, along with their corresponding boundaries [15]. These features play a crucial role in the uptake and transport of hydrogen in steels and their engineering is crucial with respect to reducing hydrogen embrittlement susceptibility. Features that typically attract hydrogen are classified as traps, a localised region in which an atom or molecule, in this case hydrogen, remains for a longer period of time than it would in a typical interstitial lattice site [46]. 
Such traps can be further categorised as either reversible or irreversible, depending on their activation energy. Reversible traps are those which hydrogen frequents for a limited time dependent upon temperature, more specifically those with an activation energy of less than $50 \mathrm{~kJ} \cdot \mathrm{mol}^{-1}$. Irreversible traps on the other hand, with activation energies greater than $50 \mathrm{~kJ} \cdot \mathrm{mol}^{-1}$, for the same temperature, show a negligible probability of escaping the trap [47]. The consequence of such trapping sites, both reversible and to a greater extent those irreversible, is a reduction in the diffusion rate and an increase in the hydrogen solubility for the steel matrix [15].

Deducing the appropriate mechanisms through which to achieve hydrogen embrittlement resistance for a particular steel depends upon the form of hydrogen ingress and the operational conditions. For such a selection process, one can categorise the desired microstructural effects into three fundamental objectives: hydrogen trapping with in-life degassing, through-life hydrogen trapping, and hydrogen ingress prevention.

Trapping with in-life degassing is achieved by a microstructure which contains traps of a suitable depth at which it is viable to degas part-way through life, without detriment to the microstructure [48] [30]. For example, for a particular application, if the hydrogen ingress rate was high enough to saturate all permissible traps within a microstructure during its lifetime, be it during processing and/or operation, a degassing treatment would be required to empty said hydrogen traps, reducing the free hydrogen content during preceding operation through renewed hydrogen trapping capacity. To permit such a degassing treatment, the traps must be shallow enough to be liberated during such a treatment, the temperature of which will often be limited due to the microstructural stability at temperature and the permissible temperatures achievable for the respective component's environment, if degassing is even viable in the first place [28]. Prevalent to bearing steels, applying degassing treatment to hydrogenated steels containing retained austenite must be done with caution as total degassing is not guaranteed. There are cases where hydrogen is at high concentrations within the retained austenite and, due to the low diffusivity and high solubility of hydrogen in said austenite, that hydrogen is retained within the phase after degassing [49]. Consequently, retained austenite behaves as a reservoir for hydrogen, gradually diffusing its contained hydrogen into the bulk ferrite when under stress, thus increasing the mobile hydrogen concentration [50]. One study by Robinson [51] found that, after degassing, a hydrogen charged carbon steel wire's embrittlement susceptibility increased. It was postulated that this was caused by the low 
temperature of the degassing treatment, limiting the liberation of hydrogen to only reversible traps. After liberation, this hydrogen was then trapped on larger defects of irreversible trapping character. As previously described, sites such as these can act as significant stress concentrators, and if hydrogen is beyond a critical concentration, upon reloading, rapid catastrophic failure can occur. Thus, the increased hydrogen concentration on such defects was postulated as being that of beyond the critical concentration for crack initiation under the applied stress and, as a result, failure resulted at a lower stress than that for the samples which did not receive a degassing treatment [51].

Through-life hydrogen trapping is achieved by a microstructure containing traps adequate in number, capacity and depth to irreversibly trap all hydrogen entering the steel during its life without saturation. This is permissible for operational environments where hydrogen ingress is not substantial. For example, bearings, such as those used in off-shore wind turbines, may accumulate up to $3 \mathrm{ppm}$ hydrogen over their lifetime [21]. Trapping this amount of hydrogen is permissible through engineered microstructural traps [52]. Hence, through-life hydrogen embrittlement resistance may be achieved without in-life degassing.

Of course, preventing ingress all together provides a solution to all operational conditions. As such, the development of hydrogen-ingress resistant coatings and microstructures is of great appeal. In bearing steels, cracking will often initiate subsurface, with the proceeding failure enhanced by hydrogen [20]. To prevent such failures, it is permissible to produce a surface layer of hydrogen resistant material which in turn reduces or eliminates hydrogen ingress. One potential ingress-inhibitor is through the use of austenite, within which the diffusivity is up to a factor of $10^{4}$ less than that of ferrite, as shown in Table 2. A surface layer of which could greatly limit hydrogen ingress in comparison to that of current bearing steels. Similarly, a coating or oxide layer could be produced to the same effect. Of course, as is the case in many applications including bearing steels, the surface morphology can play a key role in the steel's properties, such as rolling contact fatigue life, and as such, a protective surface layer or coating may not be permissible [53] [54].

Other than microstructurally-dependent hydrogen embrittlement resistance mechanisms, reducing hydrogen content and/or production in the operational environment is of critical importance and if achievable, may negate entirely the requirement for hydrogen embrittlement resistant microstruc- 
Table 2: Diffusion coefficients of hydrogen in various stainless steels at $50^{\circ} \mathrm{C}$

\begin{tabular}{lll} 
& \multicolumn{2}{c}{$([47]$ after $[55])}$. \\
\hline Steel & Matrix Phase & Diffusivity $\left(\mathrm{m}^{2} \mathrm{~s}^{-1}\right)$ \\
\hline 405 & Ferritic & $2.8 \times 10^{-12}$ \\
304 & Austenite & $1.1 \times 10^{-15}$ \\
316 & Austenite & $2.0 \times 10^{-15}$ \\
$316 \mathrm{~L}$ & Austenite & $2.4 \times 10^{-16}$
\end{tabular}

tures.

Although absent in the majority of work within the open literature, it is critical to distinguish external hydrogen from internal hydrogen, as both will have significant but very different effects on a steel's susceptibility to hydrogen embrittlement. For this review, internal hydrogen is defined as the hydrogen, molecular and atomic, that is present within the bearing steel immediately prior to operation, which is assumed to be entirely trapped by various microstructural features. External hydrogen is defined as that which enters the steel during operation and is thus expected to diffuse through the material and is again intended to be trapped by the microstructural features engineered to optimise such trapping capabilities of the steels concerned.

From what has been reviewed so far, it is evident that the microstructural traps engineered into the steels are redundant if saturated with hydrogen upon entering operation. Thus, case by case, steels must be monitored in terms of hydrogen ingress throughout their product lifecycle, and if necessary, measures taken to outgas these steels prior to operation. Given that the energy required to free the hydrogen will influence on the temperatures required for a degassing treatment, deeper traps will require higher temperatures to the extent that cost or temperature may exceed that which is economically viable or to a point at which microstructural stability becomes of concern [30]. Thus, when selecting microstructural hydrogen traps for implementation within a steel, one must consider the hydrogen ingress and microstructural stability at all processing stages, and ensure that the processed microstructure is suitable for the degrees of hydrogen ingress, the temperatures and the stresses expected through-life.

\subsection{Hydrogen Embrittlement Resistant Steels}

Bearing steels are typically designed for high strength, hardness and wear resistance, and with such a diverse range of applications, including the auto- 
motive, aerospace, nuclear and marine industry, many are prone to accelerated wear and damage from the harsh environments in which they operate [56]. The primary failure mechanism of such bearings is rolling contact fatigue, a mechanism significantly accelerated by hydrogen [22]. The following sections provide a brief description of bearing steel design, processing and rolling contact fatigue with relevance to hydrogen embrittlement.

\subsubsection{Design and Processing}

Although there are many different bearing steels with a significant range of compositions, a number have come to prominence since their introduction, these are shown in Table 1 . These steels all share a notably high carbon content of 0.71 to $1.05 \mathrm{wt} \%$ and substitutional solute contents less than $3 \mathrm{wt} \%$ [21]. Typically, carbon content is reduced in high temperature bearing steels and increased when through-hardenability is required [14]. With increasing carbon content comes increased wear resistance, higher phase fractions of carbides and retained austenite, and a reduction in the martensite start temperature [14] [57].

Current steels regarded as hydrogen embrittlement resistant are typically of low carbon content, which is typically to improve weldability, formability, ductility and corrosion resistance [14]. Titanium, niobium and vanadium additions are used to provide hydrogen trapping sites [9][58][15], both in the form of carbides and solutes, and to increase strength and wear resistance [57]. In addition to these effects, these elements have been added to retard austenite grain growth at high temperatures typical of austenitisation treatments, and improve carbide stability, which is of appeal in high temperature applications.

With current commercial as-rolled 52100 steels, the total hydrogen content is typically around the order of magnitude of $1 \mathrm{ppm}$, although electron beam melted 52100 type steel has been shown to contain as little as 0.4 ppmw [14][59]. The mean total hydrogen content for a $5210015 \mathrm{~mm}$ diameter bar during the manufacturing of the steel can be as high as $8 \mathrm{ppm}$; this content is reduced during further processing [14][60]. The hydrogen concentrations achievable in a variety of M50 bearing steel production processes are shown in Table 3.

Although currently not implemented commercially, a nanostructured superbainitic bearing steel has been proposed as an alternative to the marketdominating martensitic bearing steels [62]. Such superbainitic steels are of some appeal with respect to hydrogen embrittlement resistance. A softer 
Table 3 The effect of melting processes on gaseous impurity concentrations in M50 bearing steels ([14] after [61]).

\begin{tabular}{l|lll}
\hline Process & $\begin{array}{l}\text { Hydrogen } \\
(\text { ppmw })\end{array}$ & $\begin{array}{l}\text { Nitrogen } \\
(\mathrm{ppmw})\end{array}$ & $\begin{array}{l}\text { Oxygen } \\
(\mathrm{ppmw})\end{array}$ \\
\hline Air melting + vacuum degassing & 3.2 & 120 & 46 \\
Air melting (AM) & 4.8 & 150 & 67 \\
AM + 1 vacuum arc remelt & 1.8 & 80 & 37 \\
AM + 2 vacuum arc remelt & $<1$ & 60 & 9 \\
AM + 3 vacuum arc remelt & $<1$ & 50 & 5 \\
Vacuum induction melting & $<1$ & 85 & 21 \\
Vacuum induction melting & $<1$ & 60 & 6 \\
+ vacuum arc remelting & & & \\
\hline
\end{tabular}

lower-bainitic structure of 52100 steel has been commented as potentially affording a longer rolling contact fatigue life when in the presence of hydrogen due to the increased ductility and toughness ([14] after [63]). The austenite content, once exceeding a percolation threshold, allows the structure to resist the penetration of hydrogen [64].

\subsection{Hydrogen in Rolling Contact Fatigue}

The shakedown period of RCF, identified by an accumulation of defects within the stress fields, holding back both the yielding and proceeding work hardening mechanism, depends upon a steel's residual stress and microstructure. The presence of retained austenite has been shown to increase this shakedown period due to the transformation of austenite into martensite under stress [65]. Although the interactions of retained austenite and hydrogen have been suggested in the literature, most notably with respect to providing hydrogen reservoirs [49], they are little understood. One family of steels where this is most relevant is that of TRIP steels. Hydrogen lowers the critical stress at which dislocations nucleate [66], increases their mobility, and reduces the equilibrium distance between said dislocations [5]. As such, one can deduce that the transformation of austenite to martensite, as observed in TRIP steels, will occur at lower stresses in the presence of hydrogen and the resulting dislocation density and saturation density will be increased. These dislocations will provide reversible traps for hydrogen, however the solubility of hydrogen in martensite compared to austenite is lower. Thus, It would appear hydrogen will induce strain hardening at a lower strain, and 
through enabling retained austenite to martensite transformation at lower strains, may reduce any enhanced ductility from the TRIP-effect. Ensuring total degassing of any austenite containing material is thus key not only to reduce any free hydrogen content but to prevent the loss of any possible TRIP-induced ductility.

A steady-state is reached after the shakedown stage of RCF, with the rate of plastic-damage significantly lower than that during shakedown. The control within this steady-state stage is critical to rolling contact fatigue life, as during said stage, the damage rate is limited by dislocation glide and is increased with dislocation mobility [14]. This is where hydrogen is of great significance [67]. Given that dislocation climb is negligible at typical bearing operating temperatures $\left(<100^{\circ} \mathrm{C}\right)$, due to insufficient energy to promote self-diffusion and dislocation pinning due to carbon, dislocation mobility is limited. However, in the presence of hydrogen, dislocation mobility is thought to be greatly enhanced, accelerating the fatigue damage process by enhancing the self diffusion process [67] [68].

To evaluate the rolling contact fatigue life of novel hydrogen resistant bearing steels, ideally one would carry out full-scale bearing endurance testing, reproducing the operating environment as realistically as possible, including the decomposition of lubricant and any other hydrogen ingress mechanisms active in the intended application. However, these tests are uneconomical and as such, accelerated testing using bearing elements is the most common form of bearing life analysis [69]. These simpler tests have been found to reproduce bearing lives accurately compared to full-scale testing, providing a cost-effective, widely applied, and thus reproducible, method of evaluating the rolling contact fatigue life of novel bearing steels [69]. It is permissible, using such a testing method, that in situ hydrogen charging or a precharged specimen could be utilised and have its hydrogen embrittlement resistance evaluated [15].

It should be noted, however, that results from element testing can be misleading due to differing stress states in comparison to the intended operational environment. Microstructural effects have been shown to differ between different test methods [70] and as such, it is essential that consistency is kept when comparing and conducting experiments and in evaluating the resulting data on rolling contact fatigue life.

White etching areas (WEAs) and white etching cracks (WECs) are the preliminary microstructural damage modes observed in a number of steel bearing elements. Characterised by the white appearance of the subsurface 
damage regions, nanocrystalline in nature, around $1 \mathrm{~mm}$ below the contact surface, after etching in Nital, during optical evaluation [71].

It has been shown that increased concentrations in diffusible hydrogen can enhance WEA/WEC formation [6][72] for tests varying only in diffusible hydrogen content. Diffusible hydrogen concentration was shown to be the key contributor to the initiation of WEAs [6]. There is strong evidence that WEAs can initiate with or without pre-formation of butterflies. It is believed that white etching features can initiate from inclusions, propagate and create a network, leading to failure [6][72]. It should be noted, however, that smallscale samples used in such RCF tests will have a smaller critical region within which inclusions can be located and initiated, in comparison to that of larger bearings. As such, even with industrially applicable loading conditions, the hydrogen concentration necessary to induce initiation will thus vary for RCF samples in comparison to that of larger bearings. Lower concentrations are likely to be necessary for initiation in larger bearings.

RCF tests carried out on a novel vanadium containing variant of $100 \mathrm{Cr} 6$ bearing steel by Szost et al. [15], 100Cr6+0.5V, showed that the presence of nanosized vanadium carbides resulted in no white etching areas after similar conditions to those which produced areas in its vanadium-free variant, indicating the reduction in hydrogen-embrittlement susceptability with such microstructures. However, more tests are required to conclusively affirm the benefits of vanadium carbides to reducing hydrogen-embrittlement susceptibility, and consequently increasing RCF life in the presence of hydrogen [15]. The benefits of such hydrogen traps pose great promise in various applications in reducing embrittlement. The application of such hydrogen traps isolated to the surface of a bearing, when precipitate-hardening is undesirable in the bulk, also shows promise, preventing bulk penetration by hydrogen, most notably, penetration into the damage zone where failure most commonly occurs [14].

Some of the most common hydrogen traps present in the literature, their respective steels, and the means by which the activation energies were obtained, are shown in Table 4 . In addition to vanadium carbide, a number of other carbides have been evaluated with respect to their hydrogen trapping efficiency, most notably that of titanium carbide and niobium carbide. However, these carbides have been mostly studied in low to mild carbon steels [73] [74] due to their stability and consequent difficulty to control at higher carbon contents. However, as shown in the work of Szost et al. [15], it is feasible to dissolve such stable carbides in high carbon steels using high 
temperature dissolution treatments followed by reprecipitation of carbides at lower temperatures to produce a desired microstructure. Although the high temperatures required to dissolve such carbides may be uneconomical or industrially infeasible [15], carbides could also be managed within isolated carbon lean regions, where temperatures for dissolution are more achievable.

The optimisation of nanoprecipitates, such as carbides, as hydrogen traps is crucial for future alloy design. However, the effects of coherency and carbide composition on the hydrogen trapping capacity and binding energy are little understood. Evidence shows that the activation energy of such traps is dependent on carbide-matrix interface coherency [9]. The effects of coherency for TiC-matrix interfaces on the hydrogen trapping behavior in steel was studied by Lee [9]. Incoherent titanium carbides were found to have a larger trap activation energy than semi-coherent ones, with activation energy increasing with particle size. Smaller precipitates are favoured in bearing steels due to their permissibly large number density, strengthening effects, and the detrimental effects of large incoherent carbides on the rolling contact fatigue life of bearings [14]. A study by Yamasaki and Bhadeshia [75] studied the effects of particle size and coherency on the trapping capacity of M4C3 carbides in Fe-C-Mo- $\mathrm{V}$ model steels, showing an optimum trapping capacity was achieved with a carbide size of $10 \mathrm{~nm}$ for vanadium rich carbides. Mo additions were also studied, and were shown to increase the coherency of vanadium-rich carbides. The trapping of hydrogen on carbidematrix interfaces has been validated using 3D atom probe tomography [76], showing evidence of deuterium trapping on the matrix-carbide interfaces of $10 \mathrm{~nm}$ titanium carbides. The interaction of hydrogen with the various interfaces present in typical bearing steels is complex, be it the lack of conclusive evidence or means of characterising trapping locations and atomic configurations on said interfaces, or the complications involving nonmetallic elements and their corresponding bonding effects. Given such complexity, interfaces will contain a range of trapping sites of varied binding energy, although general orientation and coherency should be reasonably consistent across the interface. However, despite no work providing a conclusive relationship of coherency-to-hydrogen trapping capacity, it is evident that a size-effect exists and this must be considered in the design of hydrogen embrittlement resistant steels. 
Table 4 Common hydrogen traps with their corresponding binding energies.

\begin{tabular}{|c|c|c|c|c|c|}
\hline Class & Trap Type & $\begin{array}{l}\text { Binding } \\
\text { Energy } \\
E_{b} \\
(\mathrm{~kJ} / \mathrm{mol})\end{array}$ & Comment & $\begin{array}{l}\text { Technique } \\
\text { (Material) }\end{array}$ & Ref. \\
\hline \multirow[t]{12}{*}{ Precip. } & $\mathrm{Mo}_{2} \mathrm{C}$ & $22-28$ & peak aged & $\mathrm{EP}$ & {$[77]$} \\
\hline & $\mathrm{Mo}_{2} \mathrm{C}$ & $21-29$ & fine precip. & $\mathrm{EP}$ & [78] \\
\hline & $\mathrm{VC}$ & 17 & coherent & EP & [79] \\
\hline & $\mathrm{V}_{4} \mathrm{C}_{3}$ & 30 & coherent & TDA (LCS) & [80] \\
\hline & $\mathrm{Fe}_{3} \mathrm{C}$ & $21-29$ & - & $\mathrm{EP}$ & [78] \\
\hline & $\mathrm{Fe}_{3} \mathrm{C}$ & 84 & incoherent & LR (MCS) & $\begin{array}{l}81] \\
{[21]}\end{array}$ \\
\hline & Epsilon carbide & 13 & - & TDA & {$[82]$} \\
\hline & AlN & 65 & - & LR & [83] \\
\hline & AlN & $>83.94$ & - & LR & [83] \\
\hline & $\mathrm{TiC}$ & 94 & incoherent & LR & {$[83]$} \\
\hline & $\mathrm{TiC}$ & $77-95$ & semi- & LR & [33] \\
\hline & $\mathrm{TiC}$ & 87 & incoherent & TDA (MCS) & [84] \\
\hline \multirow[t]{2}{*}{ Phases } & $\begin{array}{l}\text { Retained } \\
\text { austenite }\end{array}$ & 45 & & TDA (MCS) & {$[85]$} \\
\hline & $\begin{array}{l}\text { Retained } \\
\text { austenite }\end{array}$ & 55 & & (DPS) & $\begin{array}{l}{[81]} \\
{[86]}\end{array}$ \\
\hline \multirow[t]{4}{*}{ Defects } & Dislocations & $26-29$ & $\begin{array}{l}5-15 \\
\text { atoms/nm }\end{array}$ & $\mathrm{TDA}+\mathrm{EP}$ & $\begin{array}{l}{[87]} \\
{[88]} \\
{[89]} \\
{[90]}\end{array}$ \\
\hline & Grain boundary & 17 & & $(\mathrm{PI})$ & {$[92]$} \\
\hline & Grain boundary & $53-59$ & high angle & LR & [33] \\
\hline & Voids & 21 & & LR & [33] \\
\hline
\end{tabular}

Where: TDA - Thermal Desorption Analysis, EP - Electrochemical

Permeation testing, LR - Literature Review, (MCS) - medium carbon steel, (DPS) - dual-phase steel, (LCR) - low carbon steel, and (PI) - pure iron. 


\section{Summary}

A review of the published literature on hydrogen embrittlement has been presented, from which a number of conclusions can be taken.

The bulk of the literature concerns the effects of hydrogen on the mechanical properties of bearing steels. Hydrogen has been shown to increase dislocation mobility, drastically reduce the RCF life and enhance the formation of WEAs and WECs [6][72]. The most supported mechanisms of embrittlement are hydrogen enhanced decohesion (HED) [4] and hydrogen enhanced localised plasticity (HELP) theory [5]. Despite the lack of a conclusive theory, it is established that hydrogen enhances plasticity local to crack tips, increases slip deformation and reduces the critical stress required to propagate cracks [6].

Almost all instances of hydrogen embrittlement begin with the decomposition of molecules into hydrogen at the material surface. During the decomposition of lubricant oil, the mechanism thought to be most prevalent to bearings, the composition of the oil plays a crucial role on the degree of hydrogen ingress and consequent embrittlement. Active sites are generated upon the nascent surface of the bearing steel after the removal of the oxide layer due to rubbing [23]. Tribochemical decomposition of the oil then occurs upon these active sites with hydrogen and gaseous hydrocarbons desorbed as reaction products. The desorbed amount of hydrogen and hydrocarbons increased linearly with rolling velocity and parabolically with load [23]. In addition, there appears a critical load beyond which decomposition occurs [23]. Oil containing water may also increase ingress rates due to water splitting.

The control of hydrogen content in steels is an important task for steelmakers, just a few parts per million of dissolved hydrogen can induce hydrogen flakes (hairline cracks), blistering, loss of ductility and increased porosity [27], especially in larger castings [28]. Steelmakers will often carry out a degassing treatment after solidification. Degassing at a low temperature $\left(<200^{\circ} \mathrm{C}\right)$ can liberate weakly trapped hydrogen and concentrate it in deeply trapping microstructural features which can, in some cases, increase the embrittlement susceptibility due to higher stress concentrations [31]. With current commercial as-rolled 52100 steels, the total hydrogen content permissible is said to be around $1 \mathrm{ppm}$, although electron beam melted 52100 type steel has been shown to contain as little as $0.4 \mathrm{ppmw}$ [14][59]. The mean total hydrogen content for a $5210015 \mathrm{~mm}$ diameter bar can be as high as 8 ppm, 
the distribution is fairly uniform but ranges from $7-15 \mathrm{ppm}$ to $0.5-2.5 \mathrm{ppm}$ at the surface and core respectively, these contents are reduced during further processing [14][60].

Hydrogen trapping with in-life degassing, through-life hydrogen trapping, and hydrogen ingress prevention are possible means to reduce hydrogen embrittlement. When selecting microstructural hydrogen traps for implementation within a steel, one must consider the hydrogen ingress and microstructural stability at all processing stages, and ensure that the processed microstructure is suitable for the degrees of hydrogen ingress, the temperatures and the stresses expected through-life [30].

Current steels regarded as hydrogen embrittlement resistant are typically of low carbon content, which is typically to improve weldability, formability, ductility and corrosion resistance [14]. Titanium, niobium and vanadium additions are used to provide hydrogen trapping sites $[9,58,15]$, both in the form of carbides and solutes, and to increase strength and wear resistance [57]. RCF tests carried out on a novel vanadium containing variant of $100 \mathrm{Cr} 6$ bearing steel, $100 \mathrm{Cr} 6+0.5 \mathrm{~V}$, showed that the presence of nanosized vanadium carbides resulted in no white etching areas after similar conditions to that which produced areas in its vanadium-free variant, indicating the reduction in hydrogen-embrittlement susceptability with such microstructures [15]. However, more tests are required to conclusively affirm the benefits of vanadium carbides to reducing hydrogen-embrittlement susceptibility, and potentially increasing RCF life in the presence of hydrogen [15].

Although this review focuses on that of bearing steels, the application of such hydrogen embrittlement resistant design technology is far reaching. A notable application is to that of nickel based alloys where hydrogen embrittlement is also of concern. The application of nanostructured microstructures containing suitable interfaces for hydrogen trapping could be implemented in a similar way for such alloys, with a number of hydrogen traps having already been identified, such as $\mathrm{TiC}[93,94]$. Such nanostructures are also relevant with respect to radiation embrittlement resistance, as nanoparticles have been shown to provide defect recombination sites as well as trapping hydrogen and helium [95]. Although significant research is being conducted to develop technologies for resisting hydrogen embrittlement, it is evident that the entire manufacturing process and intended operating environment must be evaluated to develop novel microstructures that suit both the manufacturing routes and operational environments.

*Acknowledgements 
This work was supported by the SKF Engineering and Research Centre and financed by AB SKF and the Engineering and Physical Sciences Research Council [Programme grant number EP/L014742/1].

[1] D. Hardie, E. Charles, A. Lopez, Hydrogen embrittlement of high strength pipeline steels, Corrosion Science 48 (12) (2006) 4378 - 4385.

[2] B. Gu, J. Luo, X. Mao, Hydrogen-facilitated anodic dissolution-type stress corrosion cracking of pipeline steels in near-neutral ph solution, Corrosion 55 (1) (1999) 96-106. doi:10.5006/1.3283971.

[3] A. Varias, A. Massih, Simulation of hydrogen embrittlement in zirconium alloys under stress and temperature gradients, Journal of Nuclear Materials 279 (2-3) (2000) 273-285.

[4] H. Birnbaum, et al., Mechanisms of hydrogen related fracture - a review, Second International Conference on Corrosion-Deformation Interactions. CDI'96.

[5] H. Birnbaum, P. Sofronis, Hydrogen-enhanced localized plasticity - a mechanism for hydrogen-related fracture, Materials Science and Engineering: A 176 (1-2) (1994) 191-202.

[6] M. Evans, A. Richardson, L. Wang, R. Wood, Effect of hydrogen on butterfly and white etching crack (WEC) formation under rolling contact fatigue (RCF), Wear 306 (2013) 226-241.

[7] R. Thomson, Brittle fracture in a ductile material with application to hydrogen embrittlement, Journal of Materials Science 13 (1) (1978) 128142 .

[8] H. G. Nelson, Chapter 8 - hydrogen embrittlement, Treatise On Materials Science and Technology - Embrittlement of Engineering Alloys 25 (1983) 275-361.

[9] Sung Man Lee, Jai Young Lee, The effect of the interface character of TiC particles on hydrogen trapping in steel, Acta Metallurgica 35 (11) (1987) 2695-2700.

[10] G. Pressouyre, I. Bernstein, An example of the effect of hydrogen trapping on hydrogen embrittlement, Metallurgical Transactions A 12 (5) (1981) 835-844. 
[11] S. Bechtle, M. Kumar, B. Somerday, M. Launey, R. Ritchie, Grainboundary engineering markedly reduces susceptibility to intergranular hydrogen embrittlement in metallic materials, Acta Materialia 57 (14) (2009) $4148-4157$.

[12] S. P. Yueming Liang, On hydrogen-induced void nucleation and grain boundary decohesion in nickel-base alloys, Journal of Engineering Materials and Technology 126 (4).

[13] M. Zhao, Z. Guo, S. Chen, H. Liang, L. Rong, Hydrogen-induced modification in the deformation and fracture of a precipitation-hardened $\mathrm{FeNi}$ based austenitic alloy, J. Mater. Sci. Technol. 30 (11) (2014) 1155-1159.

[14] H.K.D.H. Bhadeshia, Steels for bearings, Progress in Materials Science 57 (2012) 268-435.

[15] B. Szost, R. Vegter, P.E.J. Rivera-Diaz-del-Castillo, Developing bearing steels combining hydrogen resistance and improved hardness, Materials Design 43 (2013) 499 - 506.

[16] A. Barnoush, H. Vehoff, Recent developments in the study of hydrogen embrittlement: Hydrogen effect on dislocation nucleation, Acta Materialia 58 (16) (2010) 5274-5285.

[17] W. M. Garrison Jr, N. R. Moody, , Chapter 12: Hydrogen embrittlement of high strength steels, Gaseous Hydrogen Embrittlement of Materials in Energy Technologies, Volume 1: The problem, its characterisation and effects on particular alloy classes 1 .

[18] M. Kohara, T. Kawamura, M. Egami, Study on mechanism of hydrogen generation from lubricants, Tribology Transactions 49 (1) (2006) 53-60. doi:10.1080/05698190500486324.

[19] H.K.D.H. Bhadeshia, W. Solano-Alvarez, Critical assessment 13: Elimination of white etching matter in bearing steels, Materials Science and Technology 31 (9).

[20] N. Kino, K. Otani, The influence of hydrogen on rolling contact fatigue life and its improvement, JSAE Review 24 (2003) 289-294. 
[21] B. Szost, Hydrogen trapping in bearing steels: mechanisms and alloy design, Ph.D. thesis, Department of Material Science and Metallurgy, Cambridge University (2012).

[22] J. Ciruna, H. Szieleit, The effect of hydrogen on the rolling contact fatigue life of AISI 52100 and 440C steel balls, Wear 24 (1) (1973) 107118.

[23] R. Lu, Investigation of decomposition of hydrocarbon oil on the nascent surface of steel, Tribology Letters 27 (1) (2007) 25-30.

[24] F. Al-Faqeer, H. Pickering, Analytical methods for studying cathodic hydrogen charging into metals under competitive adsorption conditions, effects of hydrogen on materials, in: Proceedings of the 2008 International Hydrogen Conference, 2009, pp. 248-291.

[25] C. Grimes, O. Varghese, S. Ranjan, Hydrogen generation by water splitting, in: C. Grimes, O. Varghese, S. Ranjan (Eds.), Light, Water, Hydrogen, Springer US, 2008, pp. 35-113.

[26] F. Dean, Measurement of hydrogen permeation through structural steel sections of varying thickness at $19^{\circ} \mathrm{C}$, Materials Science and Technology 21 (3) (2005) 347-351.

[27] R. K. Dayal, N. Parvathavarthini, Hydrogen embrittlement in power plant steels, Frontiers in Materials Science (2005) 431-453.

[28] K. N. Jha, M. K. Sardar, N. N. Jha, S. Chakraborty, Hydrogen control during steel making for medium carbon wheels, Scandinavian Journal of Metallurgy 32 (6) (2003) 296-300.

[29] R. Dekkers, et al., Steel cleanliness and hydrogen in liquid steel, in: VII International Conference on Molten Slags Fluxes and Salts, The South African Institute of Mining and Metallurgy, 2004.

[30] D. Gaude-Fugarolas, Understanding hydrogen redistribution and designing a new hydrogen extraction method, Materials Today: Proceedings 2, Supplement 2 (2015) S393 - S400, joint 3rd UK-China Steel Research Forum amp; 15th CMA-UK Conference on Materials Science and Engineering. 
[31] M. J. Robinson, R. M. Sharp, The effect of post-exposure heat treatment on the hydrogen embrittlement of high carbon steel, Corrosion 41 (10) (1985) 582-586. doi:10.5006/1.3582987.

[32] T. Harris, M. Ragen, R. Spitzer, The effect of hoop and material residual stresses on the fatigue life of high speed rolling bearing, Tribology Transactions 35 (1992) 194-198.

[33] G. Pressouyre, A classification of hydrogen traps in steel, Metallurgical Transactions A 10 (10) (1979) 1571-1573.

[34] P. Scott, A review of environment-sensitive fracture in water reactor materials, Corrosion Science 583 (8-9).

[35] R. Dekkers, et al., Steel cleanliness and hydrogen in liquid steel, VII International Conference on Molten Slags Fluxes and Salts, The South African Institute of Mining and Metallurgy (2004) 753-762.

[36] T. Kushida, Hydrogen entry into steel by atmospheric corrosion, ISIJ International 43 (4) (2003) 470-474.

[37] K. Garca, A. Morales, C. Barrero, J. Greneche, New contributions to the understanding of rust layer formation in steels exposed to a total immersion test, Corrosion Science 48 (9) (2006) 2813 - 2830.

[38] L. C. Weiner, Kinetics and mechanism of hydrogen attack of steel, Corrosion 17 (3) (1961) 137t-143t. doi:10.5006/0010-9312-17.3.109.

[39] M.W.D. Van Der Burg and E. Ven Der Giessen, A continuum damage relation for hydrogen attack cavitation, Acta Materialia 45 (7) (1997) $3047-3057$.

[40] F. Ropital, Corrosion and degradation of metallic materials: Understanding of the phenomena and applications in petroleum and process industries, IFP Publications 58-60.

[41] R. Oriani, The diffusion and trapping of hydrogen in steel, Acta Metallurgica 18 (1) (1970) 147 - 157. doi:http://dx.doi.org/10.1016/00016160(70)90078-7.

[42] G. Pressouyre, A classification of hydrogen traps in steel, Metallurgical Transactions A 10 (10) (1979) 1571-1573. 
[43] R. Oriani, The diffusion and trapping of hydrogen in steel, Act Metallurgica 18 (1970) 147-157.

[44] E. K. M. Rath, Coupled grain growth and precipitation modeling in multi-phase systems, Materials Science Forum 753 (2013) 357-360.

[45] E. Cabrol, C. Bellot, P. Lamesle, D. Delagnes, E. Povoden-Karadeniz, Experimental investigation and thermodynamic modeling of molybdenum and vanadium-containing carbide hardened iron-based alloys, Journal of Alloys and Compounds 556 (2013) 203 - 209.

[46] A. Turnbull, M. Carroll, J. Ferriss, Analysis of hydrogen diffusion and trapping in a $13 \%$ chromium martensitic stainless steel, Acta Metallurgica 37 (7) (1989) 2039-2046.

[47] E. Hillier, The effect of zinc-cobalt electroplating on the hydrogen embrittlement of high strength steel, Ph.D. thesis, Cranfield University (2001).

[48] R. Viswanathan, Chapter 7: Petroleum reactor pressure-vessel materials for hydrogen service, in: R. Viswanathan (Ed.), Damage Mechanisms and Life Assessment of High Temperature Components, ASM International, 1995, pp. 329-382.

[49] K. G. Solheim, J. K. Solberg, J. Walmsley, F. Rosenqvist, T. H. Bjrn, The role of retained austenite in hydrogen embrittlement of supermartensitic stainless steel, Engineering Failure Analysis 34 (2013) 140 149 .

[50] C. Andreone, A. Marut, Influence of the retained austenite in the hydrogen embrittlement in AISI 4340, Scripta Metallurgica 24 (1990) 14531458 .

[51] M. Robinson, R. Sharp, The effect of post exposure heat treatment on the hydrogen embrittlement of high strength steel, Corrosion - NACE 41 (10) (1985) 582-586.

[52] T. Tarui, S. Yamasaki, Evaluation method of delayed fracture property of overcoming techniques of delayed fracture of high strength steels, Journal of the Iron and Steel Institute of Japan 88 (2002) 612-619. 
[53] S. Stewart, R. Ahmed, Rolling contact fatigue of surface coatingsa review, Wear 253 (1112) (2002) 1132 - 1144.

[54] D. D. Nelias, et al., Role of inclusions, surface roughness and operating conditions on rolling contact fatigue., ASME. J. Tribol. 121 (2) $240-$ 251.

[55] F. Fischer, J. Svoboda, E. Kozeschnik, Interstitial diffusion in systems with multiple sorts of traps, Model Simulation Materials Science 21.

[56] I. M. Felsen, R.W. McQuaid, J.A. Marzini, Effect of seawater on the fatigue life and failure distribution of flood-lubricated angular contact ball bearings, ASLE Trans. 15 (1972) $8-17$.

[57] D. Hanlon, W. Rainforth, C. Sellars, The effect of processing route, composition and hardness on the wear response of chromium bearing steels in a rolling-sliding configuration, Wear 203204 (1997) 220 - 229, 11th International Conference on Wear of Materials.

[58] M. Ohnuma, J. ichi Suzuki, F.-G. Wei, K. Tsuzaki, Direct observation of hydrogen trapped by nbc in steel using small-angle neutron scattering, Scripta Materialia 58 (2) (2008) 142 - 145.

[59] Y. Fimenko, A. Kuslitskii, D. Chaban, G. Karpenko, B. Movchan, Effect of electron-beam melting upon the properties of grade shkh15 ballbearing steel, Soviet Materials Science 1 (1966) 333-335.

[60] T. Imran, B. Jacobson, A. Shariff, Quantifying diffused hydrogen in AISI-52100 bearing steel and in silver steel under tribo-mechanical action: Pure rotating bending, sliding-rotating bending, rolling-rotating bending and uni-axial tensile loading, Wear 261 (2006) 86-95.

[61] R. Schlatter, J. Stroup, Improved m50 aircraft bearing steel through advanced vacuum melting process, Journal of Vacuum Science and Technology 9 (1972) 1326-1333.

[62] W. Solano-Alvarez, E. Pickering, H. Bhadeshia, Degradation of nanostructured bainitic steel under rolling contact fatigue, Materials Science and Engineering A 617 (2014) 156-164. 
[63] J. Hampshire, J. Nash, G. Hollox, Materials evaluation by flat washer testing, Rolling contact fatigue testing of bearing steels, ASTM (1982) 46-66.

[64] L. Fielding, E. J. Sung, D. K. Han, H.K.D.H. Bhadeshia and D. W. Suh, Hydrogen diffusion and the percolation of austenite in nanostructured bainitic steel, Proceedings of the Royal Society A 470 (2014) 20140108.

[65] G. Popescu, A. Gaeblli, G. Espejel, B. Wemekamp, Micro-plastic material model and residual fields in rolling contacts, Journal of ASTM International 3.

[66] A. Barnoush, M. Asgari, R. Johnsen, Resolving the hydrogen effect on dislocation nucleation and mobility by electrochemical nanoindentation, Scripta Materialia 66 (6) (2012) 414-417.

[67] A. Barnoush, Hydrogen embrittlement, Ph.D. thesis, Universitat Des Saarlandes (December 2011).

[68] R. McLellan, L. Yang, Hydrogen-vacancy interaction in palladium, Acta Metallurgica Materialia 43 (6) (1995) 2463-1467.

[69] J.J.C. Hoo, Rolling contact fatigue testing of bearing steels, ASTM STP 771.

[70] J. Kang, Mechanisms of microstructural damage during rolling contact fatigue of bearing steels, Ph.D. thesis, Darwin College, University of Cambridge (2013).

[71] M. H. Evans, White structure flaking (WSF) in wind turbine gearbox bearings: effects of butterflies and white etching cracks (WECs), Materials Science and Technology 28 (1) (2012) 3-22.

[72] R. H. Vegter, J. T. Slycke, The role of hydrogen on rolling contact fatigue response of rolling element bearings, Journal of ASTM International $7(2)$.

[73] O. Stern, Elektrochem. Angew. Phys. Chem. 30 (1924) 508-516.

[74] K. Hayashi, evaluation of hydrogen embrittlement susceptibility for sheet steels, Procedures of JSAE annual congress 18 (4) (2004) 5-8. 
[75] S. Yamasaki, H. Bhadeshia, M4C3 precipitation in Fe-C-Mo-V steels and relationship to hydrogen trapping, Proceedings of the Royal Society A 462 (2006) 2315-2330.

[76] K. Takahashi, J. Kawakami, The first direct observation of hydrogen trapping sites in tic precipitation-hardening steel through atom probe tomography, Scripta Materialia 63 (2010) 261-264.

[77] G. Pressouyre, F. Faure, ASTM, Philadelphia, PA (1988) 353-371.

[78] S. Hinotani, Y. Ohmori, F. Terasaki, Materials Science and Engineering 76 (1985) 57-69.

[79] F. Gehmann, H. Grabke, E. Riecke, The University Press, London (1995) $216-226$.

[80] G. Pressouyre, I. Bernstein, An example of the effect of hydrogen trapping on hydrogen embrittlement, Metallurgical Transactions A 12A (1981) 825-844.

[81] I. Maroef, Hydrogen trapping in ferritic steel weld metal, International MAterials Reviews 4 (47) (2002) 191-223.

[82] G. W. Hong and J. Y. Lee, Scripta Metallurgica A 17 (1983) 301-314.

[83] J. P. Hirth, Metallurgical Transactions A (1980) 861-890.

[84] S. Lee, J. Lee, Hydrogen trapping phenomena in metals with b.c.c. and f.c.c. structure by the thermal desorption analysis technique, Surface and Coatings Technology 28 (1986) 301-314.

[85] D. Enomoto, M. Hirakami, Thermal desorption analysis of hydrogen in high strength martensitic steels, Metallurgical and Materials Transactions A (2011) 1-10.

[86] A. Park, Y. Maroef, A. Landau, Retained austenite as a hydrogen trap in steel welds, Welding Journal 27S (2002) 27-35.

[87] G. W. Hong and J. Y. Lee, Acta Metallurgica 32 (10) (1984) 1581-1589.

[88] Y. Mine, Y. Horita, Materials Transactions 53 (5) (2012) 773-785. 
[89] P. C. Rivera, V. Ramunni, P. Bruzzoni, Corrosion Science 54 (2012) 106-118.

[90] R. Thomas, D. Li, R. Gangloff, J. Scully, Metallurgical and Materials Transactions A 33 (2002) 1991-2004.

[91] S. Frappart, A. Oudriss, X. Feaugas, J. Creus, J. Bouhattate, F. Thebault, L. Delattre, H. Marchebois, Scripta Materialia 65 (2011) 859-862.

[92] W. Choo, J. Lee, Thermal analysis of trapped hydrogen in pure iron, Metallurgical Transactions A 13 (1982) 135-140.

[93] B. Pound, A comparison of hydrogen ingress behavior in Alloys 625 and 716, Scripta Metallurgica et Materialia 29 (11) (1993) 1433 - 1438.

[94] B. Pound, The effect of aging on hydrogen trapping in precipitationhardened alloys, Corrosion Science 42 (11) (2000) 1941 - 1956.

[95] A. Rowcliffe, L. Mansur, D. Hoelzer, R. Nanstad, Perspectives on radiation effects in nickel-base alloys for applications in advanced reactors, Journal of Nuclear Materials 392 (2) (2009) 341 - 352. 